\title{
Exclusão "da" e "na"
educação superior:
os desafios de acesso
e permanência
para a população trans
}

Exclusion "from" and "in" higher education: challenges on access and continuance for the transexual population

\author{
Milena Carlos de Lacerda* \\ Guilherme Almeida**
}

\begin{abstract}
Resumo - Considerando que o ingresso nas instituições universitárias não é experiência comum às/aos travestis e transexuais brasileiras/ os, o presente artigo objetiva refletir acerca dos desafios que atravessam o acesso e a permanência das pessoas trans, a partir da experiência da Universidade Federal do Tocantins. Neste aspecto, a pesquisa documental empreendeu uma análise dos dois dispositivos centrais que aparecem como os indicadores mais evidentes da formalização desta população no ambiente universitário: o nome social e o uso autorreferido dos banheiros. Essas questões relacionam-se à adequação do ambiente educacional, à promoção da diversidade sexual e à expressão/identidade de gênero como condição indispensável para garantir o direito à educação às pessoas em condições precárias de vida social, alijadas dos direitos fundamentais e expostas à margem do convívio social.
\end{abstract}

Palavras-chave: acesso; permanência; universidades; nome social.

\begin{abstract}
Taking into consideration that admission to universities is not a regular experience to Brazilian transvestites and transexuals, this article aims to reflect upon the challenges that are faced by trans people during access and staying at the Federal University of Tocantins (UFT). The documental research undertook an analysis of two central documents that work as indicators of formal acceptance of this population on the university environment: adoption of chosen name and self-determination of which restroom to use. These questions relate to the adaptation of the educational environment, to the promotion of sexual diversity, and to the notion of gender/identity expression as fundamental to assure the right to education to people who live in precarious conditions of social life, whose basic rights are often denied and that are living on the margins of society.
\end{abstract}

Keywords: access; continuance; universities; chosen name.

\footnotetext{
* Assistente Social, Professora do Curso de Serviço Social da Universidade Federal do Tocantins. Doutoranda em Serviço Social no Programa de Pós-Graduação em Serviço Social da Faculdade de Serviço Social da Universidade do Estado do Rio de Janeiro (FSS/UERJ). E-mail: milenalacerdaseso@gmail.com. ORCID: https://orcid.org/0000-00031299-8296.

** Assistente Social, Doutor em Saúde Coletiva pelo IMS/UERJ e Professor do Curso de Serviço Social da Universidade Federal do Rio de Janeiro. E-mail: gsdealmeida@gmail.com. ORCID: https://orcid.org/0000-0001-7355-6606.
} 


\section{Introdução}

O presente artigo é oriundo da dissertação de mestrado que versou sobre a construção e implementação do direito ao nome social e ao uso dos banheiros por pessoas trans ${ }^{1}$ na Universidade Federal do Tocantins (UFT). A partir da pesquisa documental, a dissertação empreendeu uma análise exploratória dos modos como o acesso e permanência das pessoas trans na educação aparecem nas regulações estaduais do Tocantins e a descrição do processo de construção do direito ao nome social e do uso autorreferido dos banheiros na UFT.

Neste artigo, aproximamo-nos dos desafios que atravessam o acesso e permanência das pessoas trans no ensino superior a partir da eleição de dois dispositivos centrais: o nome social e o uso autorreferido dos banheiros nas instituições de ensino superior (IES), particularizando a experiência da UFT.

A partir dessas reflexões, a análise da educação no contexto da contrarreforma do Estado e a proliferação de narrativas e práticas conservadoras em torno do gênero e da sexualidade requer a centralidade da dialética no fazer investigativo, ao passo que possibilita a mediação ontológica do universal, particular e singular, haja visto os impactos cotidianos na vida social das pessoas trans e as relações sociais mais amplas da produção e apropriação da riqueza social.

É importante lembrar que a disputa política partidária manifesta nas eleições de 2018 no Brasil agudizou o projeto de sucateamento da educação superior, a "cultura do ódio", a perseguição ideológica e a asfixia financeira às universidades empreendida pela ascensão de governos conservadores e autoritários no país. Trata-se de um projeto do capital para educação, na sua mistificação como mercadoria.

No intuito de desvelar esses desdobramentos no cenário nacional, partiremos do pressuposto dialético-crítico para pensar a materialidade da vida social, oriunda dos "modos de ser e determinações da existência" (MARX, 2013), através da pesquisa bibliográfica e análise documental das políticas educacionais voltadas às pessoas trans. Em vista da abordagem qualitativa, lançamos mão do levantamento de registros documentais situados em matérias jornalísticas de 2013-2018 com repercussão institucional, estadual e regional acerca dos direitos das pessoas trans no estado do Tocantins.

A discussão das diferenças e das desigualdades foi direcionada pelo feminismo interseccional, indo além da combinação e sobreposição das formas das desigualdades e ressaltando a capacidade de agenciamento da população trans no cenário institucional adverso.

${ }^{1}$ A identificação de pessoas trans é dada pela pluralidade das expressões de gênero em avesso à cisgeneridade. Nesse trabalho, optamos pela abordagem que incorpora apenas os/as sujeitos que se autodeclaram travestis e transexuais. 


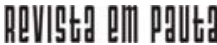

\} EXCLUSÃO “DA" E "NA" EDUCAÇÃO SUPERIOR - LACERDA, M. C.; ALMEIDA, G.

DOI: $10.12957 /$ rep.2021.56087

Com base no espectro de pessoas trans inseridos/as nas instituições universitárias, objetivamos refletir acerca das condições de acesso e permanência, considerando que o apagamento das identidades trans não se apresenta exclusivamente nas universidades, pois as violências e violações a que são acometidas manifestam-se ao longo das suas vidas. Vale mencionar ainda que o escopo aludido anteriormente não é representativo, pois o ingresso no ambiente universitário não é experiência comum às travestis e transexuais brasileiras/os, posto que a entrada na educação superior pressupõe uma formação na educação básica.

De antemão, cabe recuperar que esse estudo adentra a zona periférica de uma temática de invisibilidade, com sujeitos considerados "abjetos" no tecido social, situada em uma região periférica no cenário nacional e alocada numa instituição universitária sucateada. É desse lugar de (re) existência que nos pronunciamos, pois a apreensão das concepções hegemônicas sobre gênero e sexualidade nesse território, que em geral se pauta na defesa da família nuclear burguesa, está em disputa com as organizações coletivas que culminaram nos parcos direitos da população LGBTI+ (Lésbicas, Gays, Travestis, Transexuais, Intersexuais).

\section{A afirmação do direito à universidade: entre o ser e o não ser}

Aludir às questões mais abrangentes que envolvem o acesso e permanência no contexto universitário pressupõe retomar a lógica do capital, da programática neoliberal, do processo de mercantilização das políticas sociais e da precarização do trabalho que impulsiona reformas e ajustes imbricados no metabolismo do capital. À despeito de não traçarmos uma reflexão aprofundada da educação nos limites deste artigo, a concebemos como uma dimensão da vida social alicerçada no sentindo ontológico do trabalho. Como política social, o direito a educação é um direito humano fundamental, garantido constitucionalmente.

Esse pano de fundo oferece balizas teóricas para refletir sobre os desafios do acesso e permanência em diferentes níveis e modalidades educacionais. Os índices indicam que o capital privado protagoniza a oferta da educação superior, acompanhando a terapêutica neoliberal da "democratização" e "acessibilidade". A proliferação da "venda" dos cursos é mascarada pela possibilidade de acesso e acompanha os ajustes norteados pelas diretrizes dos organismos multilaterais com a parceria da iniciativa privada.

As questões do acesso e permanência estão sedimentadas sob um quadro profundamente desigual da sociedade brasileira, pois desde o seu surgimento tardio, a universidade privilegia a formação das elites sociais. Por esse ângulo, o mapeamento do acesso e permanência da população 


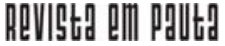

\} EXCLUSÃO “DA" E "NA" EDUCAÇÃO SUPERIOR - LACERDA, M. C.; ALMEIDA, G. \}

DOI: $10.12957 /$ rep.2021.56087

trans em sua particularidade implica a avaliação da expansão do ensino superior e seus impactos no acesso e permanência para as pessoas cisgênero ${ }^{2}$.

O próprio ingresso no ensino superior está subordinado a processos de seleção que foram se alterando e se diversificando ao longo dos anos. Gisi (2006) pontua que os processos seletivos para a entrada na educação superior mascaram uma hierarquia socialmente existente, pois conferem um poder simbólico a quem já desfruta de um poder real, na medida que só escolhe os que já estão escolhidos, corporificando uma seleção que já ocorre na própria trajetória de vida do/a estudante. Por esse motivo que as questões envolvendo o acesso e permanência não podem restringir-se à entrada nos portões das universidades, pois esta entrada está atrelada a um percurso anterior, que não envolve somente o cumprimento obrigatório da educação básica, mas as condições objetivas de existência.

Os conteúdos meritocráticos dos mecanismos de exclusão não operam somente no acesso às IES, mas nas possibilidades de permanência. Tratar desse conjunto de desigualdades requer considerar as discriminações históricas praticadas contra os sujeitos sociais excluídos das universidades e alijados do direito à educação. Na mesma proporção, é necessário reconhecer as lutas sociais travadas pelos movimentos sociais, sobretudo pelas ações afirmativas no âmbito da universidade.

Em se tratando da permanência, faz-se necessário recuperar aspectos próprios da rotina universitária que podem ser sobrepostos com o turno, a predileção dos cursos, o período integral, a modalidade de ensino (presencial, semipresencial ou à distância), o caráter público ou privado, a inserção no estágio obrigatório, as atividades extracurriculares, o acesso ao material didático, as limitações concretas de locomover-se à universidade, o vínculo trabalhista, o respeito ao nome social, a focalização dos auxílios da política da assistência estudantil, o exercício da maternidade, entre outras. São questões que se inter-relacionam com as condições objetivas e subjetivas da vida dos/as universitários/as e repercutem no número reduzido de concluintes em relação aos ingressantes.

É nesta articulação que a plenitude do acesso - permanência e conclusão - imbrica-se com as dimensões de classe social, da raça/etnia e gênero. Os índices revelam maior presença de mulheres no ensino superior. Contudo, há de se considerar quais cursos, turnos e modalidades nos quais as mulheres, tanto na rede privada ou pública estão vinculadas. Gisi (2006) alerta que, embora com maior acesso ao ensino superior e com bom desempenho, elas não se orientam para as profissões mais rentáveis e consideradas com maior prestígio econômico, por exemplo.

\footnotetext{
2 Dumaresq (2014) evidencia que "cisgeneridade" é apenas uma distinção classificatória, pois diz respeito à norma em que pessoas trans são definidas, tendo em vista sua associação com uma condição natural, essencial e padrão por meio de uma hierarquia superiorizada, que não é passível de uma análise patologizante nem tampouco precisa ter seu gênero legitimado.
} 
Entretanto, não podemos tomar as questões de acesso e permanência apenas sob a dinâmica do capital, mas reconhecer e visibilizar a correlação de forças em disputa, principalmente quando remetemos à mobilização dos coletivos negros inseridos nas universidades e das ações do movimento negro que protagonizaram a criação das políticas afirmativas e de inclusão social.

Não podemos deixar de mencionar as experiências dos pré-vestibulares comunitários como um dos instrumentos da luta em prol da democratização da educação superior no Brasil, que se constituíram não somente como espaço de qualificação para os/as trabalhadores/as negros/as, mas para a resistência e reinvindicação em torno de uma militância e da identidade negra, direcionando-se para a formação crítica das pautas históricas que envolvem as questões do trabalho, educação e raça/etnia (HENRIQUES, 2017).

As chamadas "políticas reparatórias" passam a ser reconhecidas pelo Estado, notadamente a partir dos anos 2000, com ações voltadas a educação superior, estabelecendo novas dinâmicas no que tange ao acesso e à permanência no país.

Sueli Carneiro (2011) aponta que a reivindicação das cotas e políticas de ações afirmativas pelo movimento negro representa a sua confirmação como sujeito de direitos, consciente de sua condição de credor social de um país que promoveu a acumulação primitiva de capital a partir da exploração massiva do trabalho escravo. Ao longo desse período histórico, a autora enfatiza que o Brasil não ofereceu políticas de reparação aos negros na abolição e permanece negando a integração social por meio das múltiplas formas de exclusão racial, das quais o não acesso à educação é uma das mais perversas.

Não por acaso, a relação entre educação e o mundo do trabalho dos jovens e adultos da classe trabalhadora, em que consta uma parcela considerável da população negra, ocorre de forma contrária, pois é a inserção no trabalho, bem como as dificuldades decorrentes dessa relação que geralmente fomentam o retorno ao ambiente educacional, justamente para reinserir-se ou permanecer no mercado de trabalho. Por esse motivo que a luta para acessar e permanecer no ensino superior diz respeito à ampliação das chances de inserção e permanência no mercado de trabalho (HENRIQUES, 2017).

As políticas afirmativas representam mudanças significativas no sistema educacional brasileiro. Não obstante, as condições de acesso, permanência e de formação acadêmica estão distantes de promover uma efetiva universalização do direito à educação, principalmente na quadra histórica de corte dos gastos públicos e do "contingenciamento" de verbas das universidades federais.

Com base nessas aproximações, no próximo tópico refletiremos sobre o nome social e o uso autorreferido dos banheiros para as pessoas trans, 


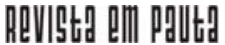

\} EXCLUSÃO “DA" E "NA" EDUCAÇÃO SUPERIOR - LACERDA, M. C.; ALMEIDA, G. \}

DOI: $10.12957 /$ rep.2021.56087

particularizando a experiência da UFT, tendo em vista que a ausência desses dispositivos associa-se com a negação de direitos fundamentais para determinada parcela da população que, em geral, não ocupa o espaço da universidade.

\section{O direito a "conta gotas": análise do acesso e permanência da população trans nas universidades}

O acesso e permanência nas instituições universitárias é recorrentemente difundido pelo senso comum como mérito individual. Nas práticas discriminatórias perpetradas na universidade, o gênero, a raça/etnia e a sexualidade ocupam lugar central e decorrem da naturalização do estigma e do preconceito em torno das hierarquias sociais.

A categorização social é realizada pela norma regulatória do heterossexismo e do regramento binário de gênero como demarcações de fronteiras, as quais não se deve problematizar, tampouco transgredir. A existência dos excluídos que são incluídos de outro modo na teia dessas relações perpassa as questões de permanência na universidade, transitando entre ocultamento, estigma e abjeção. Ao lesionar o princípio da dignidade humana, essa discriminação assume a forma da violência física e da violência não física.

\begin{abstract}
A violência física, mais visível e brutal, atinge diretamente a integridade corporal, quando não chega às raias do homicídio. A segunda forma de violência, não-física, mas não por isso menos grave e danosa, consiste no não reconhecimento e na injúria. O não-reconhecimento, ou o reconhecimento de modo inferiorizado, configura uma forma de ostracismo ou subjugação social, que nega ou subestima o valor de movo de ser ou de viver, favorecendo condições para que ocorra o tratamento degradante e insultuoso das pessoas que assim são ou vivem (RIOS; RESADORI, 2018, p. 632).
\end{abstract}

De todo modo, as violências transfóbicas são vislumbradas como casos esporádicos e pontuais e não como um fenômeno alicerçado institucionalmente, ao passo que se atomiza as práticas de subjugação social. A omissão das instituições indica a própria dificuldade em endossar o debate sobre gênero e sexualidade na arena pública, ao se negar a incorporar o conjunto de saberes e conhecimentos que a própria universidade produz.

As/os travestis e transexuais, cujas marcas de dissidência no plano da identidade de gênero estão inscritas no corpo, não necessariamente evadem da universidade ${ }^{3}$, mas são constantemente expulsas/os dela pela discriminação e estigma a que estão submetidas/os, constituindo a parcela

${ }^{3}$ Lima (2013) retoma a política do armário de Sedgwick para afirmar que os/as travestis e transexuais não tem a opção de manter-se camuflados, pois se expressam na corporeidade que apresenta a materialidade da divergência à heteronormatividade. 


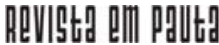

\} EXCLUSÃO “DA" E "NA" EDUCAÇÃO SUPERIOR - LACERDA, M. C.; ALMEIDA, G. \}

DOI: $10.12957 /$ rep.2021.56087

da população com maiores dificuldades de permanência na escola e de inserção no mercado de trabalho. Ainda que não se tenha dados precisos no país, estimativas apontam que são poucas as/as travestis e transexuais que conseguem acessar a educação superior. A dificuldade de concluir o nível médio e superior pelo conjunto de violências incide no mercado de trabalho, alocando-as/os, majoritariamente, no exército industrial de reserva que é estruturado pela lei geral da acumulação capitalista.

Na contramão dessas iniciativas, as IES experimentam formas de resistência à intolerância em relação à diversidade sexual e à identidade/ expressão de gênero, produzindo processos contra-hegemônicos. A legitimação dessas ações tem se constituído como campo de disputas, ocasionando avanços, ainda que parcos, protagonizados pelos coletivos e grupos organizados de militância LGBTI+.

Como meio de combater a exclusão e mobilizar o acesso dessa população às universidades, foi criado um conjunto de cursos preparatórios para as pessoas trans em várias regiões do país para reverter o quadro histórico de exclusão nessas instituições ${ }^{4}$. Esses espaços de acolhida e socialização primam não somente pelo repasse dos conteúdos necessários à aprovação, mas reivindicam a questão identitária, a promoção da diversidade de gênero e sexual, bem como o acesso às políticas sociais de educação, saúde e segurança pública.

Temos ainda a criação de políticas e ações afirmativas para as pessoas trans adentrarem no ensino superior em 15 instituições públicas do país, através das reservas de vagas nos processos seletivos de graduação e pós-graduação. Não obstante, esse esforço está atrelado à vontade política das instituições universitárias, que regulam as demandas dos Coletivos e Movimento LGBTI+, dado que não possui previsão legal.

Essa ampliação das cotas específicas para as pessoas trans tem multiplicado as reações contrárias e judiciais na sociedade civil, sob a alegação de inconstitucionalidade e favorecimento político-ideológico, principalmente com a escalada conservadora e a cruzada anti-gênero mobilizada em diversas partes do globo e, mais precisamente, no atual contexto político, econômico e social brasileiro.

A visibilidade das questões de gênero e sexualidade no seio da sociedade brasileira vincula-se ao esforço do Movimento Feminista e Movimento LGBTI+, cujos embates para afirmar-se como sujeito de direito geram outras maneiras de pautar essas temáticas, desafiando inclusive, no limite da sobrevivência, os modelos hegemônicos.

Cabe-nos questionar em que medida a universidade reitera a heteronormatividade e promove a transfobia institucional. De que forma a universidade se configura como espaço capaz de naturalizar ou enfrentar as

${ }^{4}$ De acordo com o Relatório As fronteiras da educação: a realidade dxs estudantes trans no Brasil (2019) elaborado pelo Instituto Brasileiro Trans de Educação (IBTE), o Brasil possui 23 cursinhos preparatórios para pessoas trans no país. 
\} EXCLUSÃO "DA" E "NA" EDUCAÇÃO SUPERIOR - LACERDA, M. C.; ALMEIDA, G. \}

DOI: $10.12957 /$ rep.2021.56087

violências baseadas nas hierarquias raciais, sexuais e de gênero? Em que medida a UFT assegura um espaço plural e democrático para a permanência das pessoas trans?

\section{A população trans na arena universitária: a inflexão do nome social e do uso autorreferido dos banheiros na Universidade Federal do Tocantins}

Vai afastar bastante né, em todos os termos, em diploma, por exemplo quando você for chamada numa fila, você ser chamada pelo nome que você quer, pelo nome que você se identifica, pelo nome que você acha, pelo nome que você é. (TV ANHANGUERA, 2018).

O texto desta epígrafe foi retirado de um vídeo gravado pela TV Anhanguera, em 2 fevereiro de 2018. A reportagem se inicia com os apresentadores contextualizando o decreto nacional que regulamenta o nome social. Em seguida, eles apresentam o decreto municipal que disciplina o nome social em Araguaína, no interior do Tocantins. A cena seguinte é um salão de beleza que mostra duas mulheres trans trabalhando, enquanto a repórter narra a situação de preconceito que incide sobre a população trans no estado. Márcia e Giovana declaram-se travestis, podem ser consideradas étnico-racialmente negras e estão na faixa etária de 28-35 anos. No salão de Márcia, a repórter mostra o certificado de cabeleireira que consta o nome de registro e outro certificado sem preenchimento, aguardando a oportunidade de ser identificada pelo nome social, inclusive com alterações nos documentos legais. Giovana declara que o nome social não é aceito sequer nos momentos de compra e emissão de nota fiscal e que o respeito ao direito de personalidade depende do nível de proximidade e vontade do/a atendente.

Ainda no contexto do Tocantins, a UFT é a única instituição universitária do estado a regulamentar a utilização do Nome Social de estudantes travestis e transexuais no sistema oficial de registro e controle acadêmico. Ela o fez através da Resolução n. 25/2015. Tal normativa determina a inclusão do nome social dos/as alunos/as nos respectivos registros acadêmicos da graduação, extensão e da pós-graduação de todos os campi da UFT cujo nome civil não reflita adequadamente sua identidade de gênero.

O reconhecimento desse direito foi pauta dos coletivos e organizações LGBTI+, que no ano de 2013 protocolaram uma documentação que sustenta a defesa da utilização do nome social no âmbito da universidade. Não obstante a objetividade desses procedimentos, a minuta ficou estagnada durante dois anos, sob o argumento da ausência de recursos.

Os protagonistas do processo registraram a falta de vontade política e administrativa, uma vez que o nome social não onerava financeiramente a UFT e assegurava a execução de uma função básica da universidade, 


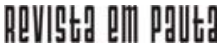

\} EXCLUSÃO "DA" E "NA" EDUCAÇÃO SUPERIOR - LACERDA, M. C.; ALMEIDA, G. \}

DOI: $10.12957 /$ rep.2021.56087

portanto sua implementação não demandava levantamento de recursos extraordinários nem incluía procedimentos de difícil execução pela universidade.

Os coletivos universitários protagonizaram uma série de ações políticas e denúncias nas emissoras locais, requerendo a aprovação imediata do nome social. Com a polêmica e a imagem negativa da instituição sendo propagada, os gestores da UFT instituíram a portaria de regulação do nome social, tornando-se a $27^{\text {a }}$ universidade do país a garantir o uso do nome social no país.

O uso do nome social nos estabelecimentos universitários é fundamental para assegurar o reconhecimento e respeito à identidade de gênero. Por conseguinte, salientamos que o acesso e a permanência não se esgotam no nome social e no uso dos banheiros, mas em estabelecer um ambiente seguro e plural para a comunidade universitária, sem preconceito, discriminação e exclusão.

A pesquisa As Fronteiras da Educação (CANTELLI et al., 2019), publicada em janeiro de 2019 pelo IBTE, demonstra que o nome social, o uso dos banheiros e ausência de apoio psicopedagógico são indicadores dos principais obstáculos da população trans no ambiente educacional.

Visto que a limitação a esses aspectos incide nos direitos constitucionais fundamentais de primeira geração (os tipos ideais dos direitos civis), enquanto que temos de abranger ainda os direitos sociais e políticos dessas pessoas. O não reconhecimento do nome, por exemplo, é um interdito cotidiano, pois configura-se como privação de um direito civil, de expressão e de personalidade, pois envolve a exclusão, distinção e restrição.

O reconhecimento do nome social nas instituições e repartições, sobretudo públicas, representa uma medida de ampliação da cidadania e dos direitos fundamentais para travestis e transexuais, visto que "o nome social é o nome através do qual a pessoa deseja ser identificada, uma vez que o nome civil não condiz com o modo de vida que a/o travesti ou a/o transexual assume na atualidade" (LIMA, 2013, p. 11).

Em torno deste debate, Berenice Bento (2014) contesta a proliferação de normas que estabelecem o respeito à identidade de gênero das pessoas trans na esfera das microrrelações. A autora argumenta que o Brasil possui uma criatividade que o singulariza no cenário internacional, pois o modus operandi historicamente observável das elites é feito à "conta-gota" em relação ao reconhecimento das conquistas dos considerados "excluídos".

O nome social acompanha a forma lenta e descontínua das leis que antecederam a Lei Áurea, do direito ao voto das mulheres e das regulamentações tardias na esfera do trabalho na história brasileira. A autora questiona a solução à brasileira que damos à negação do respeito à identidade de gênero materializada no nome social. Testemunhamos a propagação da aprovação dessa regulamentação nas instituições públicas. Contudo, sua utilização não altera substancialmente a existência desses in- 


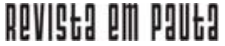

\} EXCLUSÃO “DA" E "NA" EDUCAÇÃO SUPERIOR - LACERDA, M. C.; ALMEIDA, G. \}

DOI: $10.12957 /$ rep.2021.56087

divíduos, na medida em que continuarão a ser submetidos a situações vexatórias e humilhantes, principalmente por não vir acompanhada de autonomia civil, igualdade jurídica e do acesso às políticas sociais.

Nas questões de acesso e permanência, o nome social funciona como "gambiarra política" (BENTO, 2014) ou solução paliativa para o direito básico de acesso às instituições de educação, considerando que a discriminação transfóbica é um impeditivo da permanência de indivíduos trans. Sendo assim, o nome social é a porta de entrada para os demais direitos sociais, mas ele, isoladamente, não garante a permanência na educação superior.

No que concerne às IES, Correa (2017) assinala que o nome social vem sendo regulamentado dentro das universidades públicas no Brasil, principalmente a partir do ano de 2010. Conforme os dados colhidos pela autora, até o ano de 2017, das 284 Universidades Públicas, 205 regulamentaram a possibilidade desse dispositivo nos documentos internos das instituições. Isso equivale a $72 \%$ das universidades públicas do país, sem considerar as extensões.

Vale mencionar que o nome social não é substituto da alteração do nome civil nos documentos jurídico-legais. A retificação do nome é uma das exigências das pessoas trans, pois reporta-se a forma como a pessoa se reconhece e é reconhecida socialmente. É uma das principais reinvindicações para os que vivenciam a experiência trans, pois o nome social funciona como forma de improviso na ausência da retificação.

Além disso, a mudança do nome nos documentos oficiais é um instrumento de minimização do conjunto de violências vivenciado cotidianamente. Em maio de 2018, o Supremo Tribunal Federal (STF) entendeu ser possível a alteração de nome e gênero no assento de registro civil, independente da submissão ao procedimento cirúrgico de redesignação de sexo, sem avaliação médica ou psicológica. Essa autorização possibilita que seja realizada a alteração dos documentos em cartório, sem autorização judicial. A decisão sinaliza, ainda que tardiamente, um avanço da cidadania, da liberdade e dos princípios fundamentais já pactuados na Constituição Federal. O reconhecimento civil e jurídico dos/as sujeitos/as que elaboram diferentes dissidências de gênero com as múltiplas identificações e expressões foi por um largo período histórico submetido aos protocolos médicos a partir da lógica da patologização.

A implantação do nome social não foi, contudo, acompanhada pela democratização do uso dos banheiros na UFT. Apesar das denúncias recorrentes de assédio e constrangimentos vivenciados pelas pessoas trans no interior da universidade, houve iniciativas pontuais de regularização do uso dos banheiros.

Dentro da UFT, apesar de ser um ambiente que forma professores, existe um conservadorismo muito grande. Foi uma surpresa para 
\} EXCLUSÃO “DA" E "NA" EDUCAÇÃO SUPERIOR - LACERDA, M. C.; ALMEIDA, G. \}

DOI: $10.12957 /$ rep.2021.56087

muitos [...] os banheiros eram necessários. A comunidade LGBT era atacada dentro dos banheiros que especificavam gênero. A universidade precisa ser plural e aceitar a diversidade. (JARDIM, 2017, n. p. $)^{5}$.

Com o número expressivo de divergências e polêmicas visibilizadas tanto em relatos de pessoas que se sentiam incomodadas pelo uso comum dos banheiros quanto pelos/as estudantes que evidenciavam a discriminação aos sujeitos LGBTI+, o diretor de um dos campi da UFT protagonizou a formalização do uso do banheiro unissex, solicitando a realização de debates com o objetivo de melhorar o acesso e prevenir situações "desagradáveis" para ambas as partes envolvidas. A ratificação da medida foi alvo de reações contrárias dos vereadores do município em questão, que repudiaram a instalação dos banheiros sob o argumento falacioso de que poderia ocorrer um maior número de estupros e assédios.

A problemática da negociação entre as posições rebateu no princípio ético dos direitos humanos, em que a liberdade de opressão não é liberdade de expressão, pois a intolerância não é um ponto de vista a ser considerado. O risco abstrato de um "perigo em potencial", que passa a tomar forma com o acesso das pessoas trans aos banheiros, foi chancelado pela transfobia institucional, amparada pelo cissexismo, cujo intuito foi disciplinar as pessoas trans.

O argumento contrário aos banheiros unissex fez equivaler a demanda por um direito fundamental à autorização para a ocorrência de violências nesses espaços. Não há dados sobre ocorrência de violências nesses banheiros. Além disso, cabe à universidade (e a qualquer instituição) zelar pela limpeza e segurança de qualquer banheiro. Tal argumento partiu do fato de que poderíamos ser coniventes com abusos pelo fato de defendermos o acesso ao uso autorreferido dos banheiros, como se os direitos das mulheres e homens trans fossem antagônicos ao das mulheres e homens cisgêneros, como se as mulheres e homens trans não fossem seres humanos e representassem um perigo indesejado para a sociedade (BAGAGLI, 2017).

De acordo com os argumentos trazidos à baila, reiteramos que a regulação dos banheiros, uniformes e vestuários (e demais elementos de indumentária), assim como os demais espaços segregados por gênero, devem vir em concordância com a identidade de gênero autoatribuída. Nessa linha, o Conselho Nacional de Combate à Discriminação e Promoção dos Direitos de Lésbicas, Gays, Bissexuais, Travestis e Transexuais (CNDC/LGBT) ${ }^{6}$

\footnotetext{
${ }^{5}$ Matéria intitulada "Banheiro unissex na UFT divide opiniões" veiculada na página eletrônica do Jornal do Tocantins (03/10/2017).

${ }^{6}$ Não podemos deixar de registrar que o CNDC/LGBT foi extinto pelo Governo Federal no ano de 2019, representando um ataque frontal a formulação, avaliação e monitoramento de políticas voltadas a comunidade LGBTI. Os mecanismos de participação social possibilitavam descentralizar o poder público e democratizar as políticas sociais, através do fortalecimento dos espaços de controle social com vistas a evidenciar as históricas injustiças sociais acumuladas secularmente contra população LGBTI+.
} 


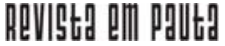

\} EXCLUSÃO “DA" E "NA" EDUCAÇÃO SUPERIOR - LACERDA, M. C.; ALMEIDA, G. \}

DOI: $10.12957 /$ rep.2021.56087

lançou a Resolução 12, que estabelece parâmetros para a garantia das condições de acesso e permanência de pessoas travestis e transexuais e todas aquelas que tenham sua identidade de gênero não reconhecida em diferentes espaços sociais nos sistemas e instituições de ensino. As orientações quanto ao reconhecimento institucional da identidade de gênero atestam que esse direito seja estendido aos estudantes adolescentes, sem a obrigatoriedade da autorização expressa dos/as responsáveis legais.

Essa resolução, que não tem força de lei, fomentou as iniciativas em algumas IES, reconhecendo o uso dos banheiros como direito inegociável. Nesse bojo, algumas universidades introduziram banheiros unissex em que não há definição de um público específico. Convém destacar a pressão exercida pelo movimento trans e LGBTI+ nesses ambientes, cobrando e denunciando a segregação e as atitudes vexatórias contra as pessoas travestis e transexuais.

Essa disputa sobre quais serão os banheiros a serem utilizados pelas pessoas trans ganha espaço nas mídias sociais, cravejada por argumentos de diversas ordens. Por um lado, temos o apoio e a afirmação de um direito fundamental. Por outro lado, a defesa da não utilização, ora recuperando argumentos religiosos, ora respaldando-se nos "inquestionáveis" aparelhos sexuais masculinos, que geram constrangimentos ao serem mostrados e violariam a intimidade e segurança das mulheres que frequentam esses locais.

Registra-se que, embora essas determinações não estejam expressas na literatura acerca dos aspectos centrais do acesso e permanência dos/as estudantes na universidade (direcionada às pessoas cisgênero que já possuem esses direitos garantidos), elas representam medidas fundamentais para assegurar sua existência nesses espaços.

\section{Considerações finais}

O abismo que se coloca entre as pessoas trans e os centros universitários relaciona-se com as múltiplas violências inscritas nas suas trajetórias escolares, familiares, pessoais e profissionais. Faz-se necessário teorizarmos para além do ingresso nos portões da universidade, já que diz respeito a um percurso formativo que envolve distintos fatores e que geralmente passam despercebidas pelas pessoas cisgênero. Por isso a necessidade de lançarmos o olhar para as outras esferas da vida social, a imersão no trabalho, os vínculos familiares, o cumprimento da educação formal, as questões identitárias, a mobilização social, além da intersecção com a classe social, o gênero e raça/etnia.

A inclusão das pessoas trans nas IES exige adequação do meio acadêmico no trato da diversidade sexual e a expressão/identidade de gênero. Essa adequação é fundamental para que as pessoas trans, que estão em condições precárias da vida social, alijadas dos direitos sociais 


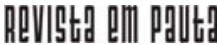

\} EXCLUSÃO "DA" E "NA" EDUCAÇÃO SUPERIOR - LACERDA, M. C.; ALMEIDA, G. \}

DOI: $10.12957 /$ rep.2021.56087

fundamentais e expostas à margem do convívio social possam acessar a formação escolar e se capacitar profissionalmente.

Correa (2017) nos atenta que embora o nome social constitua uma reinvindicação da militância trans como estratégia determinante para sobrevivência no espaço acadêmico, os regulamentos de uso do nome social se mostram insuficientes no contexto institucional. Nessa acepção, a autora sintetiza ainda que o nome social e o uso dos banheiros representam a resistência à espera, à negação e à invisibilidade trans dentro do espaço universitário por serem considerados uma estratégia de sobrevida.

Em se tratando do uso autorreferido dos banheiros, consideramos que essa divisão binária é a síntese de múltiplas determinações, sendo um espaço público e de organização da ordem social. Do ponto de vista dos direitos fundamentais, as entidades da sociedade civil de defesa dos direitos humanos sinalizam alternativas que respeitam a dignidade, liberdade, privacidade e igualdade.

Compartilhamos de algumas possibilidades: dois banheiros separados por gênero, com liberdade de utilização sem discriminação por identidade de gênero; instalações de banheiros de utilização individual, acessíveis a todos, sem distinção de sexo ou identidade de gênero; instalação de um único banheiro, de utilização coletiva e universal, com cabines individuais internas sem distinções (RIOS; RESADORI, 2015, p. 218). Salvo melhor juízo, o desconforto de listar alternativas sanitárias, os autores indicam ainda o desafio indispensável de romper a naturalização do binarismo sexual e de enxergar a grave violação de direitos fundamentais daí resultante.

Ao longo da pesquisa, percebemos o quanto o ambiente universitário pode ser hostil às travestis e transexuais, pois a violência transfóbica que expulsa as pessoas trans dos estabelecimentos universitários é o principal impeditivo da permanência na educação básica e superior. A morosidade em regulamentar o nome social revela o quanto essa pauta não é prioritária para a gestão da universidade, mesmo que em seu interior registre casos recorrentes de transfobia, sexismo e racismo.

Ao analisar os noticiários veiculados pelas mídias sociais para descrever a linha do tempo dessas regulações na UFT, identificamos o dogmatismo religioso como principal argumento para negação dos direitos da população LGBTI+, repercutindo na formação de opiniões contrárias a visibilidade das questões de gênero e sexualidade no espaço público.

Com vistas dos argumentos apresentados, ressaltamos a importância da construção de formas e estratégias de intervenção com habilidades éticas e técnicas que se desdobram em possibilidades na perspectiva do acesso, desempenho e permanência de estudantes, a partir do prisma da universalização da Educação.

Esse estudo nos revelou o caráter pragmático dos debates engendrados no ambiente educacional de uma forma geral. As políticas afirmativas para os grupos subalternizados podem ser adicionadas de forma 


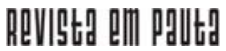

\} EXCLUSÃO "DA" E "NA" EDUCAÇÃO SUPERIOR - LACERDA, M. C.; ALMEIDA, G. \}

DOI: $10.12957 /$ rep.2021.56087

funcional, ou seja, sem alterar a forma que a universidade opera no tratamento aos sujeitos/as não hegemônicos. As iniciativas concentram-se em apaziguar os ânimos e na coexistência pacífica das relações desiguais através da "tolerância ao diferente", mas pouco polemizam acerca das hierarquias sexuais e de gênero.

Acreditamos ainda na potência da inserção crítica e continuada dessas temáticas nos espaços da instituição, complementadas com seu apoio pedagógico e científico e em articulação com o movimento social como possibilidade de aprimoramento e capacitação do corpo universitário para combater os discursos de ódio contra os dissidentes da matriz heterossexual. Nessa seara, é importante reivindicar o mapeamento e a existência de estudos pelo poder público que avaliem efetivamente como vem sendo implementadas essas resoluções nas universidades.

Como dito anteriormente, percebe-se que a distância entre esses sujeitos e os centros universitários relaciona-se com as múltiplas violências e com a intolerância que torna esse ambiente perigoso às identidades que não se encaixam nas estruturas rígidas do gênero e da sexualidade. Por outro lado, a presença desses sujeitos que confrontam a heteronormatividade também provoca a rotina da universidade, engendrando desconfortos não somente no plano epistemológico, mas na vivência cotidiana. 


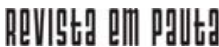

\} EXCLUSÃO "DA" E "NA" EDUCAÇÃO SUPERIOR - LACERDA, M. C.; ALMEIDA, G. \}

DOI: $10.12957 /$ rep.2021.56087

\section{Referências}

BAGLAGLI, B. P. Orientação sexual na identidade de gênero a partir da crítica da heterossexualidade e cisgeneridade como normas. Revista Letras Escreve, v. 7, n. 1, jan./jun. 2017.

BENTO, B. Nome social para pessoas trans: cidadania precária e gambiarra legal. Revista Contemporânea, v. 4, n. 1, jan./jun. 2014.

CANTELLI, A. $\mathrm{L}$ et al. As fronteiras da educação: a realidade dxs estudantes trans no Brasil. Brasil: Instituto Brasileiro Trans de Educação, 2019.

CARNEIRO, S. Racismo, sexismo e desigualdade no Brasil. São Paulo: Selo Negro, 2011.

CORREA, C. M. A. Subjetividades em trânsito: nome social, travestilidades e transexualidades em duas Universidades Públicas do Sul do Brasil. Tese (Doutorado em Ciências Humanas) - Programa de Pós-Graduação Interdisciplinar em Ciências Humanas, UFSC, 2017.

DUMARESQ, L. O cisgênero existe. Transliteração, 2015. Disponível em: http://transliteracao.com.br/leiladumaresq/2014/12/o-cisgeneroexiste/ \#: :text=N\%C3\%A3o.,denuncia\%20esse\%20pseudo\%20status\%20natural. Acesso 11 jan. 2020.

GISI, M. L. A educação superior no Brasil e o caráter de desigualdade do acesso e da permanência. Revista Diálogo Educacional, Curitiba, v. 6, n. 17, jan./abr. 2006.

HENRIQUES, C. S. Do trabalho doméstico à educação superior: a luta das mulheres trabalhadoras negras pelo direito à educação superior. O Social em Questão, n. 37, jan./abr. 2017.

JARDIM, E. Banheiro unissex na UFT divide opiniões. Jornal do Tocantins, Palmas-TO, 2017. Disponível em: https://www.jornaldotocantins.com.br/ editorias/vida-urbana/banheiro-unissex-na-uft-divide-opini\%C3\%B5es1.1360831 Acesso 11 jan. 2018.

LIMA, M. L. C. O uso do nome social como estratégia de inclusão social de transexuais e travestis. Tese (Doutorado em Psicologia Social) - PUC, São Paulo, 2013.

MARX, K. O capital: crítica da economia política. Livro I. São Paulo: Boitempo, 2013.

RIOS, R. R.; RESADORI, A. H. Direitos humanos, transexualidade e "direito dos banheiros". Revista Direito e Práxis, Rio de Janeiro, v. 6, n. 12, 2015. Disponível em: https://www.uniceub.br/media/930036/RIOS_Roger_ Raupp_RESADORI_Alice_Hertzog._Direitos_Humanos_-_Transe xualidade_e_Direito_dos_Banheiros.pdf. Acesso em: $11 \mathrm{dez} .2019$. 


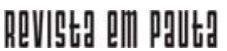

\} EXCLUSÃO "DA" E "NA" EDUCAÇÃO SUPERIOR - LACERDA, M. C.; ALMEIDA, G. \}

DOI: $10.12957 /$ rep.2021.56087

RIOS, R. R.; RESADORI, A. H. Gênero e seus/suas detratores/as: "ideologia de gênero" e violações de Direitos Humanos. Psicologia Política, v. 18, n. 43, 2018. Disponível em: http://pepsic.bvsalud.org/scielo.php?script=s ci_arttext\&pid=S1519-549X2018000300012. Acesso em: 29 set. 2019.

TV ANHANGUERA. Nome social passa a ser aceito após decreto municipal em Araguaína. Palmas-TO: Globo.com, 02 fev. 2018. Disponível em: http:/ /g1.globo.com/goias/bom-dia-go/videos/v/nome-social-passa-a-ser-aceitoapos-decreto-municipal-em-araguaina/6469869/. Acesso em 6 jun. 2018.

DOI: $10.12957 /$ rep.2021.56087

Recebido em 09 de março de 2020.

Aprovado para publicação em 20 de março de 2020.

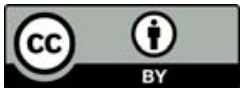

A Revista Em Pauta: Teoria Social e Realidade Contemporânea está licenciada com uma Licença Creative Commons Atribuição 4.0 Internacional. 